\title{
Risk of peripheral artery disease in human immunodeficiency virus infected individuals
}

\author{
Kevin Belgrave, Kashif Shaikh, Matthew J. Budoff \\ Los Angeles Biomedical Research Institute at Harbor UCLA Medical Center, Torrance, CA, USA \\ Correspondence to: Matthew J. Budoff, MD, FACC. Los Angeles Biomedical Research Institute at Harbor UCLA Medical Center, Torrance, CA, USA. \\ Email: mbudoff@labiomed.org. \\ Provenance: This is an invited Editorial commissioned by Guest Section Editor Maoshui Wang, MM (Department of Lab Medicine, Shandong \\ Provincial Chest Hospital, Ji'nan, China). \\ Comment on: Beckman JA, Duncan MS, Alcorn CW, et al. Association of Human Immunodeficiency Virus Infection and Risk of Peripheral Artery \\ Disease. Circulation 2018;138:255-65.
}

Submitted Sep 18, 2018. Accepted for publication Sep 30, 2018.

doi: $10.21037 /$ atm.2018.10.08

View this article at: http://dx.doi.org/10.21037/atm.2018.10.08

According to the report from the World Health Organization (WHO), 1.8 million individuals become HIV infected every year (1). Several studies have demonstrated higher incidence, prevalence and progression of subclinical atherosclerosis in HIV infected individuals as compared to general population despite optimal control of traditional risk factors $(2,3)$.

In a recently published article "Association of buman immunodeficiency virus infection and risk of peripheral artery disease" Beckman et al. (4) studied participants of Veterans Aging Cohort Study. The study consisted of 91,953 Veterans with no cardiovascular disease at baseline. Their primary outcome was incident peripheral artery disease (PAD) in HIV infected versus HIV uninfected participants, while secondary endpoints were to evaluate mortality and amputation in subjects with incident PAD. They further performed sub-analysis of events by CD4 count and viral load among HIV infected individuals. Interestingly HIV infected Veterans had a lower prevalence of traditional risk factors such as obesity, diabetes, hypertension and lowdensity lipoprotein cholesterol. The authors concluded that "infection with HIV is associated with a 19\% increased risk of PAD beyond that explained by traditional atherosclerotic risk factors. However, for those with sustained CD4 cell counts <200 cells $/ \mathrm{mm}^{3}$, the risk of incident PAD events is nearly 2-fold higher whereas for those with sustained CD4 cell counts $\geq 500$ cells $/ \mathrm{mm}^{3}$ there is no excess risk of incident PAD events compared with uninfected people". This study enriches the limited literature available on association of HIV infected and PAD. Several studies have demonstrated higher cardiovascular morbidity and mortality, including coronary heart disease (5), stroke (6) and PAD (7) in HIV infected population. Prevalence of PAD is estimated to be $1 \%$ at age 50 and $3 \%$ at 60 years in large epidemiological studies $(8,9)$. Previously, Periard el al. (7) showed the prevalence of PAD was $9.8 \%$ in HIV infected individuals $<50$ years, considerably higher than general HIV uninfected population. Although, exact mechanism for HIV-associated premature atherosclerosis has yet to be unraveled, it seems to be multifactorial, including traditional cardiovascular risk factors, combination antiretroviral therapy related side effects and increased inflammation due to direct effect of HIV infection leading to endothelial dysfunction $(5,10,11)$.

In study by Beckman et al. (4), there was a $19 \%$ increased risk of incident PAD in HIV infected individuals beyond what could be explained by traditional risk factors, suggest HIV infection as an independent risk factor for PAD. This idea is further supported by a number of studies, which demonstrated increased prevalence of non-calcified plaque in HIV infected individuals as compared to HIV uninfected after adjusting for traditional cardiovascular risk factors $(2,12)$.

Cardiologist and HIV specialists lack the tools to identify HIV individuals at high cardiovascular risk. Framingham risk score and American College of Cardiology/American Heart Association pooled cohort risk equation both seem 
to underestimate risk for cardiovascular events in HIV infected population $(13,14)$. Arterial Imaging such as ${ }^{18}$ Floruodeoxyglucose $\left({ }^{18} \mathrm{FDG}\right)$, brachial artery ultrasound and Cardiac computed tomography (CT) could be useful tools to identify HIV infected individuals at risk for developing PAD $(2,15,16)$. In another study there was an inverse relationship of HIV RNA load and brachial flow mediated dilation (16). ${ }^{18}$ FDG uptake by arterial macrophages can be used to identify arterial inflammation. The Strategies for Management of Antiretroviral Therapy study found that HIV infected patients with interrupted ART had increased inflammatory markers such as IL-6 and D-dimers $(17,18)$, these biomarkers were in turn associated with increased mortality and cardiovascular events (18).

The current study by Beckman et al. support these observations, with a low CD count $\left(<200\right.$ cells $\left./ \mathrm{mm}^{3}\right)$, incident risk of PAD was doubled, while those with CD4 count $>500$ cells $/ \mathrm{mm}^{3}$ risk was similar as compared to HIV uninfected individuals. Furthermore, 50\% of HIV infected individuals with higher viral load were deceased after diagnosis of $\mathrm{PAD}$ within 5 years.

Lastly, non-contrast and contrast cardiac CT scans can be used to identify high risk patients. Coronary artery calcium (CAC) is strong predictor of cardiovascular events. Several studies have demonstrated prognostic value of CAC in general population and in some studies of HIV infected population $(3,19,20)$. The Multicenter AIDS Cohort Study demonstrated that HIV positivity was significantly associated with higher burden of non-calcified plaque (2). PAD significantly affects quality of life and increases mortality. With 36.7 million (1) currently living with $\mathrm{HIV}$ and estimated higher prevalence and incident risk of PAD, we need better methods to identify and treat those individuals at high risk for developing PAD and other cardiovascular diseases.

\section{Acknowledgements}

None.

\section{Footnote}

Conflicts of Interest: The authors have no conflicts of interest to declare.

\section{References}

1. Smit $M$, Brinkman K, Geerlings $S$, et al. Future challenges for clinical care of an ageing population infected with HIV: a modelling study. Lancet Infect Dis 2015;15:810-8.

2. Post W, Jacobson L, Li X, editors. HIV infection is associated with greater amounts of non-calcified coronary artery plaque: MACS. Seattle, USA: 19th Conference on Retroviruses and Opportunistic Infections, 2012.

3. Hulten E, Mitchell J, Scally J, et al. HIV positivity, protease inhibitor exposure, and subclinical atherosclerosis: a systematic review and meta-analysis of observational studies. Heart 2009;95:1826-35.

4. Beckman JA, Duncan MS, Alcorn CW, et al. Association of Human Immunodeficiency Virus Infection and Risk of Peripheral Artery Disease. Circulation 2018;138:255-65.

5. Freiberg MS, Chang C-CH, Kuller LH, et al. HIV infection and the risk of acute myocardial infarction. JAMA Intern Med 2013;173:614-22.

6. Chow FC, Regan S, Feske S, et al. Comparison of ischemic stroke incidence in HIV-infected and non-HIV-infected patients in a US health care system. J Acquir Immune Defic Syndr 2012;60:351.

7. Periard D, Cavassini M, Taffé $P$, et al. High prevalence of peripheral arterial disease in HIV-infected persons. Clin Infect Dis 2008;46:761-7.

8. Zheng ZJ, Rosamond WD, Chambless LE, et al. Lower extremity arterial disease assessed by ankle-brachial index in a middle-aged population of African Americans and whites: the Atherosclerosis Risk in Communities (ARIC) Study. Am J Prev Med 2005;29:42-9.

9. Murabito JM, Evans JC, Nieto K, et al. Prevalence and clinical correlates of peripheral arterial disease in the Framingham Offspring Study. Am Heart J 2002;143:961-5.

10. Maggi P, Perilli F, Lillo A, et al. An ultrasound-based comparative study on carotid plaques in HIV-positive patients vs. atherosclerotic and arteritis patients: atherosclerotic or inflammatory lesions? Coron Artery Dis 2007;18:23-9.

11. Lai WW, Colan SD, Easley KA, et al. Dilation of the aortic root in children infected with human immunodeficiency virus type 1: The Prospective P2C2 HIV Multicenter Study. Am Heart J 2001;141:661-70.

12. Lai S, Fishman EK, Lai H, et al. Long-term cocaine use and antiretroviral therapy are associated with silent coronary artery disease in African Americans with HIV infection who have no cardiovascular symptoms. Clin Infect Dis 2008;46:600-10.

13. Monroe AK, Haberlen SA, Post WS, et al. Cardiovascular disease risk scores' relationship to subclinical cardiovascular disease among HIV-infected and HIV- 
uninfected men. AIDS 2016;30:2075-84.

14. Law M, Friis-Møller N, El-Sadr W, et al. The use of the Framingham equation to predict myocardial infarctions in HIV-infected patients: comparison with observed events in the D: A: D Study. HIV Med 2006;7:218-30.

15. Triant VA, Meigs JB, Grinspoon SK. Association of C-reactive protein and HIV infection with acute myocardial infarction. J Acquir Immune Defic Syndr 2009;51:268.

16. Torriani FJ, Komarow L, Parker RA, et al. Endothelial function in human immunodeficiency virus-infected antiretroviral-naive subjects before and after starting potent antiretroviral therapy: The ACTG (AIDS Clinical Trials Group) Study 5152s. J Am Coll Cardiol 2008;52:569-76.

Cite this article as: Belgrave $\mathrm{K}$, Shaikh K, Budoff MJ. Risk of peripheral artery disease in human immunodeficiency virus infected individuals. Ann Transl Med 2018;6(Suppl 1):S46. doi: 10.21037/atm.2018.10.08
17. Strategies for Management of Antiretroviral Therapy (SMART) Study Group, Emery S, Neuhaus JA, et al. Major clinical outcomes in antiretroviral therapy (ART)-naive participants and in those not receiving ART at baseline in the SMART study. J Infect Dis 2008;197:1133-44.

18. Kuller LH, Tracy R, Belloso W, et al. Inflammatory and coagulation biomarkers and mortality in patients with HIV infection. PLoS Med 2008;5:e203.

19. Bild DE, Detrano R, Peterson D, et al. Ethnic differences in coronary calcification: the Multi-Ethnic Study of Atherosclerosis (MESA). Circulation 2005;111:1313-20.

20. Budoff MJ, Hokanson JE, Nasir K, et al. Progression of coronary artery calcium predicts all-cause mortality. JACC Cardiovasc Imaging 2010;3:1229-36. 